\title{
Pendeteksi Nominal Uang Kertas bagi Penyandang Tunanetra Menggunakan Neural Network
}

\author{
Lilis Kurniawati , Sumantri K. Risandriya, dan Heru Wijanarko * \\ Program Studi Teknik Mekatronika, Jurusan Teknik Elektro, Politeknik Negeri Batam, \\ Batam, Indonesia \\ *Email: wijanarko@polibatam.ac.id
}

\begin{abstract}
Abstrak- Uang merupakan alat transaksi yang digunakan oleh sebagian besar masyarakat dunia untuk memenuhi kebutuhan sehari-hari. Bagi sebagian orang, melakukan kegiatan jual beli dengan menggunakan uang sangatlah mudah. Namun tidak dapat dipungkiri bahwa ada sebagian kecil dari masyarakat yang mempunyai kekurangan dalam penglihatan. Kekurangan dalam penglihatan membuat penderitanya lebih mengandalkan indra pendengaran dan perasa, sehingga penyandang Tunanetra mengalami kesulitan dalam mengenali uang. Tulisan ini membahas tentang alat bantu bagi Tunanetra yang dapat membedakan uang kertas berdasarkan warna RGB dengan menggunakan sensor TCS3200 dan memanfaatkan neural network sebagai pola pengenalan dan pembelajaran warna. Dari uji coba, nilai optimum untuk pembelajaran dengan nilai error terkecil yaitu nilai learning rate 0.8 dan jumlah node masing-masing pada hidden layer 1 dan hidden layer 2 sebanyak 5 node. Hasil yang diperoleh adalah alat yang dapat digunakan Tunanetra dalam membedakan uang kertas, dengan tingkat keberhasilan $100 \%$ untuk uang $R p 20.000$ dan $R p 100.000,93 \%$ untuk uang Rp 50.000.
\end{abstract}

Kata Kunci: Uang kertas, Tunanetra, sensor TCS3200, Neural Network

\section{Pendahuluan}

UANG merupakan alat pembayaran barang dan jasa yang sering digunakan untuk kegiatan jual beli. Bagi sebagian orang, melakukan kegiatan jual beli dengan menggunakan uang sangatlah mudah, karena memiliki indera penglihatan yang bagus. Berbeda dengan penyandang Tunanetra mengalami sedikit kesulitan saat melakukan transaksi dengan uang kertas, walaupun Bank Indonesia sebagai penerbit uang di Indonesia mengklaim bahwa uang kertas yang beredar sudah "Ramah" untuk Tunanetra [1]. Namun, masih saja terdapat kasus penipuan yang memanfaatkan kelemahan penyandang Tunanetra dalam mengidentifikasi uang [2] [3].

Penyandang Tunanerta membedakan nominal uang kertas yang dimiliki dengan mengurutkan dari yang paling besar sampai terkecil. Selain itu, penyandang Tunanetra juga membuat lipatan yang berbeda, misalkan uang Rp 100.000 dilipat menjadi dua bagian, uang Rp 50.000 dilipat sampai membentuk segitiga.

Pada penelitian sebelumnya, pengidentifikasian nominal uang kertas menggunakan teknik membaca citra digital dan algoritma Levenberg Marquardt untuk mengenali nilai nominal uang kertas tersebut. Tingkat keberhasilan mengidentifikasi uang kertas hanya mencapai 50\% untuk uang Rp 10.000 dan Rp 100.000 [4]. Kemudian penelitian mengenali uang kertas dengan menggunakan sensor TCS3200, dimana keberhasilan pembacaan frekuensi masih berpengaruh dari gradasi dan baik buruknya kondisi fisik uang kertas. Pendeteksian dilakukan untuk semua uang kertas Bank RI, dengan tingkat keberhasilan pendeteksian $60 \%$ untuk uang Rp 100.000, 75\% untuk uang Rp 50.000, dan $100 \%$ untuk uang $\mathrm{Rp} 20.000$ [5]. Alat deteksi nominal uang juga pernah dilakukan memanfaatkan metode Jaringan Saraf Tiruan (JST) [6]. Selain itu, penelitian mengklasisifikasi nominal uang kertas pernah dilakukan dengan memanfaatkan salah satu algoritma neural network [7].

Berdasarkan penelitian terdahulu, penulis bermaksud membuat alat pendeteksi nominal uang kertas bagi penyandang Tunanetra dengan memanfaatkan sensor TCS3200. Alat ini memanfaatkan perbedaan warna pada uang kertas untuk mempermudah pembacaan sejumlah nominal uang. Dari data pembacaan sensor yang didapatkan, selanjutnya akan diolah dengan menggunakan metode neural network. Hasil pengenalan yang didapatkan dari metode neural network akan diteruskan menjadi output suara, sehingga memudahkan Tunanetra untuk mengetahui nominal uang kertas tersebut.

\section{TEORI}

A. TCS 3200

IC pengubah warna cahaya ke nilai frekuensi adalah TCS3200. Sensor TCS3200 merupakan rangkaian photodioda yang disusun secara matrik array $8 \times 8$, di mana 16 buah photodioda sebagai filter merah, 16 buah photodioda sebagai 
filter biru, 16 buah photodioda sebagai filter hijau dan 16 buah photodioda sebagai filter tanpa warna. Pada Gambar 1 terlihat bahwa sensor TCS3200 memiliki dua selektor yaitu S2 dan S3 yang berfungsi untuk memilih konfigurasi filter warna photodioda yang akan digunakan.

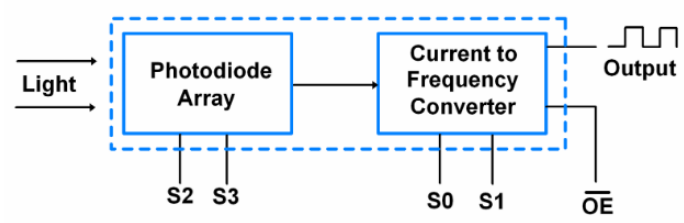

Gambar 1. Blok Diagram Sensor TCS3200 [8]

Filtering dari setiap warna dasar dilakukan secara bertahap untuk mendapatkan nilai frekuensi, serta diperlukan sebuah pengaturan atau pemograman untuk melakukan filtering tiaptiap warna tersebut [8]. Konfigurasi selektor S2 dan S3 dapat dilihat pada Tabel I:

TABEL I.

KONFIGURASI S2 DAN S3 UNTUK FILTER WARNA SENSOR TCS3200 [8]

\begin{tabular}{ccc}
\hline \hline S2 & S3 & Filter Warna \\
\hline 0 & 0 & Merah \\
0 & 1 & Biru \\
1 & 0 & Clear \\
1 & 1 & Hijau \\
\hline \hline
\end{tabular}

Photodioda akan mengeluarkan arus yang besarnya sebanding dengan warna dasar cahaya yang diterimanya. Arus ini kemudian dikonversikan menjadi pulsa digital dengan frekuensi yang sebanding dengan besarnya arus. Skala frekuensi output ini dapat diatur dengan menggunakan kaki selektor S1 dan S0.

\section{B. Neural Network}

Jaringan Syaraf Tiruan (JST) atau umumnya disebut Neural Network (NN) merupakan jaringan dari sekelompok unity pemroses kecil yang dimodelkan berdasarkan jaringan saraf manusia. NN merupakan sistem adaptif yang dapat mengubah strukturnya untuk memecahkan masalah berdasarkan informasi eksternal maupun internal yang mengalir melalui jaringan tersebut. Secara sederhana, NN adalah sebuah sistem pemodelan data statistik non-linear. NN dapat digunakan untuk memodelkan hubungan yang kompleks antara input dan output untuk menemukan pola-pola pada data [9]. Dalam memodelkan NN terdapat beberapa metode, diantaranya metode back-propagation untuk proses pembelajaran setiap data.

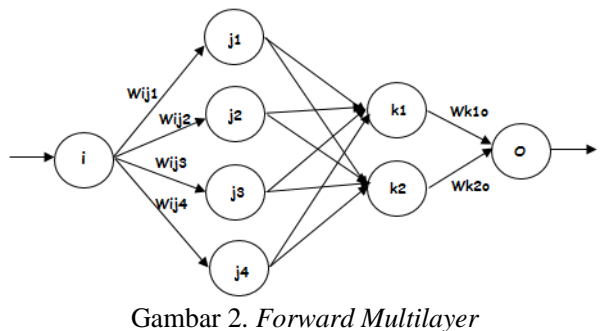

\section{MicroSD Card Adapter Module}

Modul MicroSD Card Adapter adalah modul pembaca kartu microSD, melalui sistem file dan SPI antarmuka driver, MCU untuk melengkapi sistem file membaca dan menulis kartu microSD. Pengguna Arduino langsung dapat menggunakan Arduino IDE yang dilengkapi dengan SD-card untuk inisialisasi program.

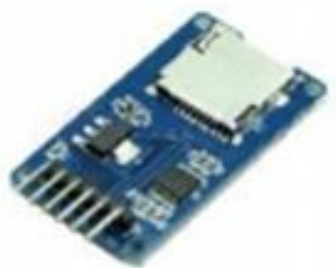

Gambar 3. SD Card Adapter Module

Fitur microSD Card Adapter Module adalah sebagai berikut:

1. Mendukung Micro SD Card dan Micro SDHC Card.

2. Tegangan operasional pada 5 Volt atau 3.3 Volt.

3. Arus operasional yang digunakan yaitu $80 \mathrm{~mA}$.

4. Menggunakan antarmuka SPI (Serial Pararel Interface)

D. Speaker

Speaker merupakan perangkat keras output yang memiliki fungsi mengeluarkan suara dari pemrosesan CPU. Speaker disebut juga alat bantu untuk keluaran suara yang dihasilkan oleh perangkat musik seperti MP3 player, DVD player dan lain sebagainya [10]. Speaker memiliki fungsi sebagai alat untuk mengubah gelombang listrik yang awalnya dari perangkat penguat suara menjadi gelombang getaran yaitu berupa suara itu sendiri. Proses dari perubahan gelombang elektromagnet menuju ke gelombang bunyi tersebut bermula dari aliran listrik yang ada pada penguat suara, kemudian dialirkan ke dalam kumparan. Pada kumparan terjadilah pengaruh gaya magnet sesuai dengan kuat-lemahnya arus listrik, dan getaran yang dihasilkan akan mempengaruhi membran.

\section{PERANCANGAN SISTEM}

\section{A. Perancangan Alat}

Perancangan alat pendeteksi nominal uang terdiri dari beberapa blok sistem, dapat dilihat pada Gambar 4 yang dihubungkan menjadi satu sistem utuh. Pembagian blok dibagi menjadi blok sensor, blok pengolahan data, dan blok keluaran. Pada blok sensor, alat menggunakan sensor warna TCS3200. Pada blok pengolahan data menggunakan arduino mega yang sudah dipasang dengan modul pengolah suara. Pada bagian keluaran adalah sebuah speaker aktif yang akan mengeluarkan bunyi nilai nominal uang dari masing-masing uang kertas yang dideteksi. 


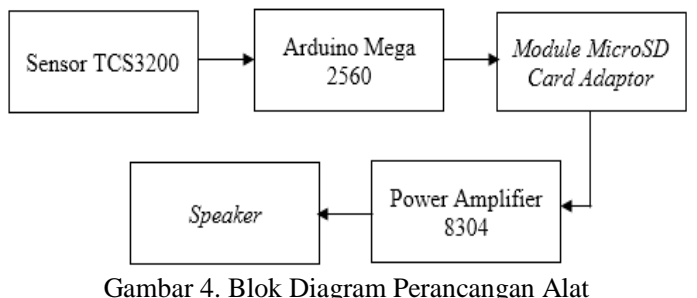

Pada perancangan sistem pengenalan untuk neural network menggunakan input sebanyak 3 buah untuk membaca maukan nilai dari red, green dan blue. Sedangkan untuk hidden layer menggunakan 2 hidden layer, dimana setiap hidden layer memiliki 5 node. Kemudian untuk output menggunakan 3 buah, yang telah diatur sesuai dengan keluaran yang diinginkan. Pada sistem minimum diberi program berbasis NN untuk mengenali nominal uang. Untuk arsitektur NN yang akan diimplementasikan dapat dilihat pada Gambar 5.

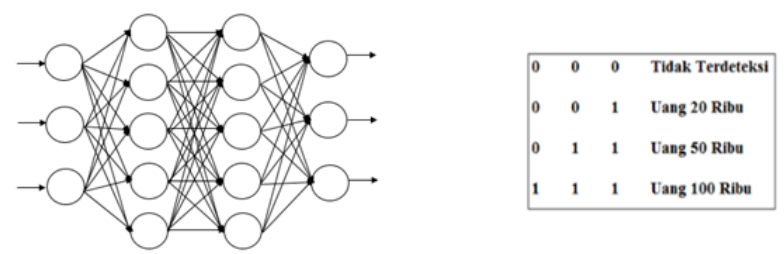

Gambar 5. Arsitektur NN Multi-Perceptron

\section{B. Diagram Alir Sistem}

Untuk dapat mengetahui nominal suatu uang kertas, terdapat beberapa tahapan seperti dijelaskan pada diagram alir sistem pada Gambar 6. Pertama, dilakukan pengambilan data uang kertas untuk NN pada PC dengan menggunakan sensor TCS3200 dan data yang didapat diubah menjadi dan dimapping sesuai dengan range keluaran yang diinginkan. Setelah data didapat, maka data tersebut akan di-learning menggunakan $\mathrm{NN}$ untuk mendapatkan nilai bobot yang sesuai. Kemudian nilai bobot disimpan sebagai data pelatihan yang akan dimasukkan ke mikrokontroler

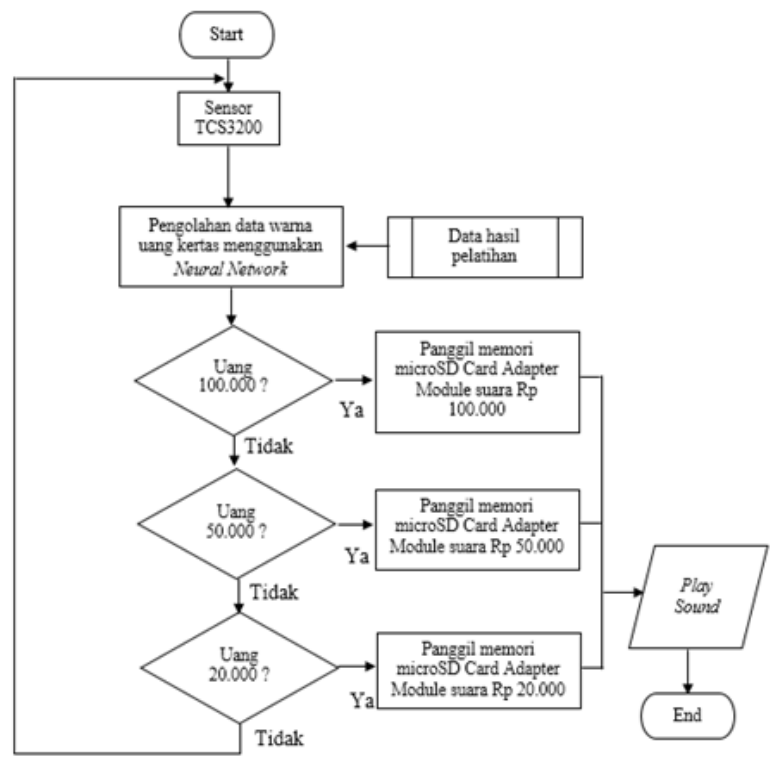

Gambar 6. Diagram Alir Sistem
Selanjutnya dilakukan pengujian dari hasil learning di PC dengan menggunakan mikrokontroler. Data pelatihan tersebut merupakan data yang akan dimasukan kedalam mikrokontroler sebagai data input. Pendeteksi nominal uang kertas dimana sensor TCS3200 akan mendapatkan data dari pancaran cahaya yang diterima photodioda ke uang kertas. Setelah data dari uang kertas terdeteksi maka, pada mikrokontroler akan diproses dengan mencocokkan nilai data uang kertas yang dideteksi dan nilai bobot yang didapat pada saat learning mrnggunakan PC. Jika proses pembacaan uang kertas sudah selesai maka, output mikrokontroler akan memanggil memori ke microSD card adapter yang terhubung ke speaker. Kemudian, speaker akan mengeluarkan suara nominal uang telah dideteksi.

\section{HASIL DAN ANALISA}

Pada pengujian menggunakan jumlah sampel data sebanyak 307 data merujuk pada lampiran, terdiri dari 100 data untuk uang Rp20.000, 100 data untuk uang Rp50.000, 100 data untuk uang Rp100.000 dan 7 data untuk kondisi normal. Terlihat perbandingan penggunaan nilai learning rate dengan jumlah iterasi.

TABEL II.

PENGUJIAN NILAI LEARNING RATE DAN JUMLAH ITERASI DENGAN TOLERANSI ERROR 0.001

\begin{tabular}{cccccl}
\hline \hline No. & $\begin{array}{c}\text { Jumlah } \\
\text { Data }\end{array}$ & $\begin{array}{c}\text { Learning } \\
\text { Rate }\end{array}$ & $\begin{array}{c}\text { Target } \\
\text { Error }\end{array}$ & Iterasi & Keterangan \\
\hline 1 & & 0.1 & & 723906 & Convergence \\
2 & & 0.2 & & 297790 & Convergence \\
3 & & 0.3 & & 237925 & Convergence \\
4 & & 0.4 & & 240688 & Convergence \\
5 & 3 & 0.5 & 0.001 & 221654 & Convergence \\
6 & & 0.6 & & 151658 & Convergence \\
7 & & 0.7 & & 127098 & Convergence \\
8 & & 0.8 & & 1302601 & Convergence \\
9 & & 0.9 & & & Not Convergence \\
\hline \hline
\end{tabular}

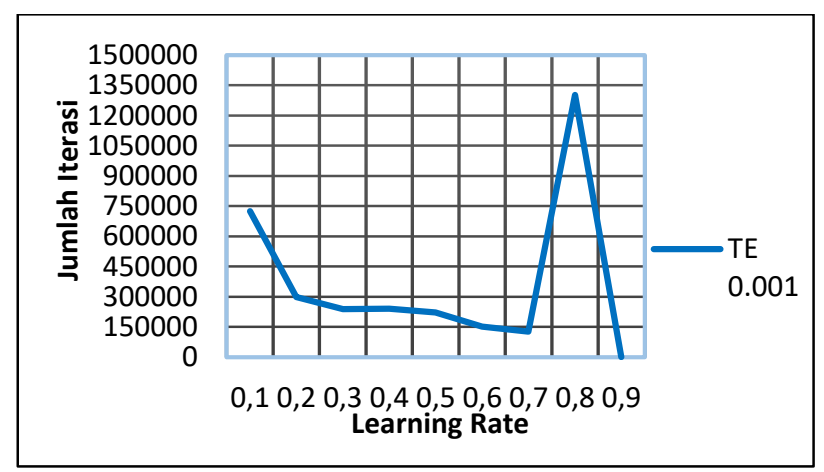

Gambar 7. Grafik Jumlah Iterasi Toleransi Error 0.001

Pada Gambar 7 terlihat prinsip nilai learning rate akan berbanding terbalik dengan jumlah iterasi yang dihasilkan untuk mendapatkan nilai bobot. Semakin kecil nilai leraning rate, maka semakin tinggi nilai iterasi yang dihasilkan untuk mendapatkan nilai bobot yang diinginkan. Dapat dilihat pada saat learning rate bernilai 0.8 , jumlah nilai iterasi tertinggi yang diperoleh sebesar 1302601 iterasi. Sedangkan pada saat 
learning rate 0.7 , jumlah nilai iterasi yang paling kecil yaitu 127098 iterasi.

TABEL III.

Pengujian Nilai AlPha Terhadap Nilai Rata-Rata ERROR

\begin{tabular}{|c|c|c|c|c|c|c|c|}
\hline \multirow{2}{*}{\begin{tabular}{|c|} 
Nilai \\
Alpha \\
\end{tabular}} & \multicolumn{6}{|c|}{ Jumlah Node } & \multirow{2}{*}{$\begin{array}{c}\text { Rata-rata } \\
\text { Error }\end{array}$} \\
\hline & 4 & 5 & 6 & & 8 & 9 & \\
\hline 0.1 & 0.0000996 & 0.0000996 & .0009939 & 0.00099 & 0.0009934 & 0.000997 & \begin{tabular}{|l|}
0.0006970 \\
\end{tabular} \\
\hline 0.2 & 0.0009944 & 0.00098 & 095 & & م 000988 & & \\
\hline 0.3 & 0.0009825 & 0.0009926 & 0.0009941 & 0.0009898 & 0.0009941 & 0.0009987 & 0.0009920 \\
\hline 0.4 & 0.0005611 & \begin{tabular}{|l|}
0.0009667 \\
\end{tabular} & \begin{tabular}{|l|}
0.0009605 \\
\end{tabular} & 0.0009 & 0.0009 & 0.0009816 & \begin{tabular}{|l|l|}
0.0009078 \\
\end{tabular} \\
\hline 0.5 & 0.0008828 & .0009691 & \begin{tabular}{|l|}
0.0009967 \\
\end{tabular} & 103 & 0.0009536 & 0.0009477 & 0.0009547 \\
\hline 0.6 & 0.0001922 & 0.0008389 & 0.0009775 & 0009248 & 0.0003370 & 0.0009854 & 0.007093 \\
\hline 0.7 & 0.0003069 & \begin{tabular}{|l|l|}
0.0009727 \\
\end{tabular} & 0.0005369 & 0.0002272 & 0.0003458 & 0.0000980 & 0.0004146 \\
\hline 0.8 & 0.0004199 & 0 & 0.0004306 & 0,0000115 & \begin{tabular}{|l|l|} 
\\
\end{tabular} & 0.0009796 & 0.0003192 \\
\hline 0.9 & & & & & & & 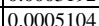 \\
\hline
\end{tabular}

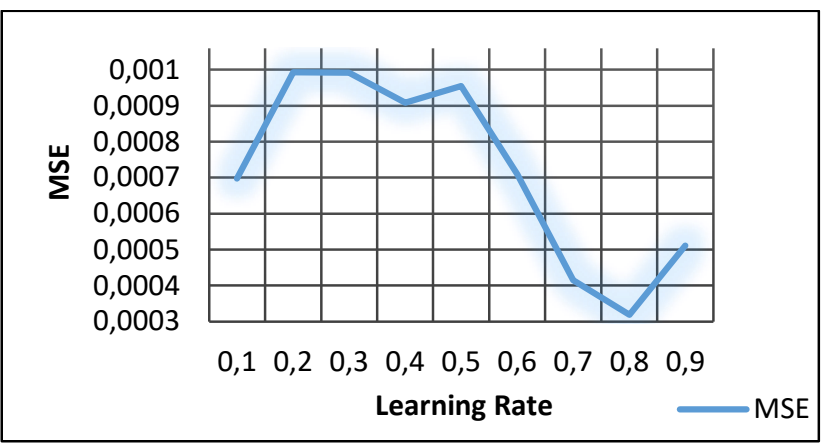

Gambar 8. Grafik pengujian nilai alpha terhadap nilai rata-rata error

Sesuai dengan Gambar 8, dapat kita lihat bahwa data pengujian hubungan antara nilai alpha dan nilai rata-rata error berdasarkan percobaan banyaknya jumlah node untuk mendapatkan parameter nilai optimum pembelajaran pada suatu struktur jaringan syaraf tiruan. Nilai rata-rata error tertinggi yaitu 0.0009926 dengan nilai alpha 0.2 , dan untuk rata-rata error terendah yaitu 0.0003192 dengan nilai alpha 0.8 . Parameter nilai optimum pembelajaran didapatkan dari nilai alpha 0.8, terlihat bahwa jumlah node yang memiliki nilai error terendah yaitu saat masing-masing jumlah hidden layer 1 dan hidden layer 2 berjumlah 5 node. Kemudian parameter tersebut yang dipilih untuk pengujian selanjutnya, dikarenakan nilai errornya yang paling kecil.

TABEL IV.

PENGUJian TOlERANSI ERROR DAN KeTEPATAN PEMBaCAAN TERHADAP NOMINAL UANG KERTAS

\begin{tabular}{|c|c|c|c|c|c|c|}
\hline Pengujian & LR & $\mathrm{TE}$ & $\begin{array}{c}\text { Jumlah } \\
\text { Node }\end{array}$ & Nominal & $\begin{array}{c}\text { Banyaknya } \\
\text { Uang }\end{array}$ & Keberhasilan \\
\hline \multirow{3}{*}{1} & \multirow{3}{*}{0.8} & \multirow{3}{*}{0.1} & \multirow{3}{*}{5} & 20.000 & 15 lembar & $100 \%$ \\
\hline & & & & 50.000 & 15 lembar & $93 \%$ \\
\hline & & & & 100.000 & 15 lembar & $100 \%$ \\
\hline \multirow{3}{*}{2} & \multirow{3}{*}{0.8} & \multirow{3}{*}{0.01} & \multirow{3}{*}{5} & 20.000 & 15 lembar & $100 \%$ \\
\hline & & & & 50.000 & 15 lembar & $93 \%$ \\
\hline & & & & 100.000 & 15 lembar & $100 \%$ \\
\hline \multirow{3}{*}{3} & \multirow{3}{*}{0.8} & \multirow{3}{*}{0.001} & \multirow{3}{*}{5} & 20.000 & 15 lembar & $100 \%$ \\
\hline & & & & 50.000 & 15 lembar & $93 \%$ \\
\hline & & & & 100.000 & 15 lembar & $100 \%$ \\
\hline \multirow{3}{*}{4} & \multirow{3}{*}{0.8} & \multirow{3}{*}{0.0001} & \multirow{3}{*}{5} & 20.000 & 15 lembar & $100 \%$ \\
\hline & & & & 50.000 & 15 lembar & $93 \%$ \\
\hline & & & & 100.000 & 15 lembar & $100 \%$ \\
\hline \multirow{3}{*}{5} & \multirow{3}{*}{0.8} & \multirow{3}{*}{0.00001} & \multirow{3}{*}{5} & 20.000 & 15 lembar & $100 \%$ \\
\hline & & & & 50.000 & 15 lembar & $93 \%$ \\
\hline & & & & 100.000 & 15 lembar & $100 \%$ \\
\hline
\end{tabular}

Pengujian keberhasilan pengenalan uang kertas dengan beberapa jenis pengujian telah dilakukan menggunakan 45 lembar uang kertas yaitu 15 lembar untuk uang Rp20.000, 15 lembar untuk uang Rp50.000 dan 15 lembar untuk uang Rp100.000. Tabel IV menunjukan presentase keberhasilan program dalam mengidentifikasi nominal uang. Tingkat keberhasilan pengidentifikasian uang yang paling rendah yaitu untuk uang $\mathrm{Rp}$ 50.000, dimana tingkat keberhasilan pendeteksian hanya 93\%. Keberhasilan pendeteksian uang Rp 50.000 ini dipengaruhi oleh ukuran uang yang lebih kecil dari akrilik pada bagian mekanik. Sedangkan untuk uang $\mathrm{Rp}$ 20.000 dan $\mathrm{Rp} 100.000$ tingkat keberhasilannya sampai dengan $100 \%$.

TABEL V.

PENGUJIAN JUMLAH ITERASI TERHADAP BANYAKNYA JUMLAH NODE DI HIDDEN LAYER 1 DAN HIDDEN LAYER 2

\begin{tabular}{cccccccc}
\hline \hline \multirow{2}{*}{ No. } & \multirow{2}{*}{ LR } & \multicolumn{6}{c}{ Jumlah Iterasi } \\
\cline { 3 - 8 } & & Node 4 & Node 5 & Node 6 & Node 7 & Node 8 & Node 9 \\
\hline 1 & 0.1 & 723906 & 407389 & 379144 & 374233 & 383443 & 404319 \\
2 & 0.2 & 297790 & 245600 & 229636 & 228715 & 237004 & 253582 \\
3 & 0.3 & 237925 & 185428 & 170999 & 168850 & 175604 & 188191 \\
4 & 0.4 & 240688 & 145518 & 121879 & 118502 & 121879 & 122186 \\
5 & 0.5 & 221654 & 124642 & 94249 & 927714 & 96091 & 103766 \\
6 & 0.6 & 151658 & 93942 & 84118 & 87188 & 89951 & 81662 \\
7 & 0.7 & 127098 & 337393 & 268318 & 271388 & 303009 & 231170 \\
8 & 0.8 & 1302601 & 889993 & 233320 & 235776 & 260029 & 64469 \\
9 & 0.9 & $\sim$ & $\sim$ & 486288 & 385899 & 311298 & 103458 \\
\hline \hline
\end{tabular}

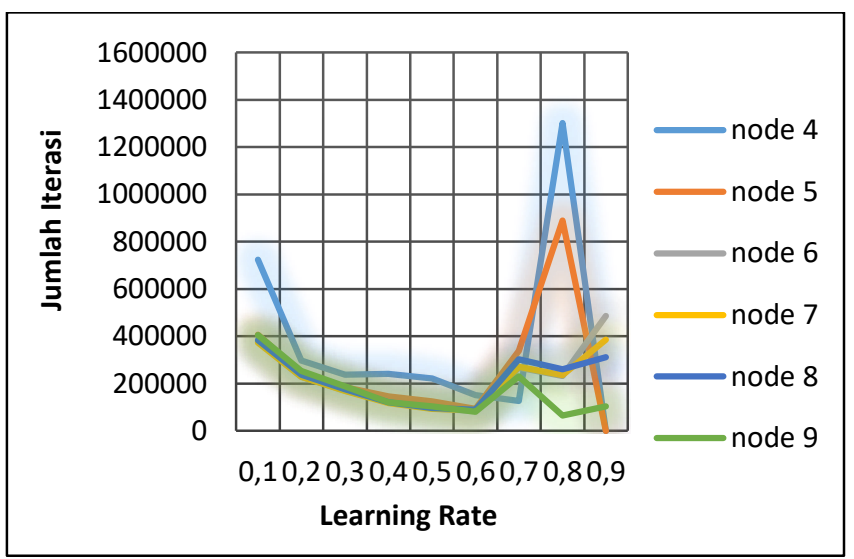

Gambar 9. Grafik pengujian jumlah iterasi terhadap banyaknya jumlah node di hidden layer 1 dan hidden layer 2

Gambar 9 merupakan grafik pengujian jumlah iterasi terhadap banyaknya jumlah node pada hidden layer 1 dan hidden layer 2. Dapat dilihat pada learning rate 0.8 nilai iterasi tertinggi diperoleh sebesar 1302601 iterasi, pada penggunaan jumlah node 5 buah. Sedangkan pada learning rate 0.8 nilai iterasi yang paling kecil yaitu 64469 iterasi pada penggunaan dengan jumlah node sebanyak 9 buah. Besar kecilnya nilai iterasi dipengaruhi oleh jumlah node dan besarnya learning rate. Apabila learning rate semakin besar dan jumlah node semakin sedikit, dapat mempengaruhi jumlah iterasi menjadi semakin besar bahkan menjadi tidak konvergen. Kondisi tidak konvergen terjadi pada learning rate 0.9 saat jumlah masing-masing node 4 dan 5 .

\section{KESIMPULASN DAN SARAN}

Berdasarkan hasil dan analisa maka penerapan neural network pada data yang dikenal telah sesuai dengan keluaran yang diinginkan. Dari seluruh pengujian yang dilakukan, maka 
dapat diambil beberapa kesimpulan. Parameter nilai optimum untuk pembelajaran dengan nilai error terkecil yaitu nilai learning rate 0.8 dan jumlah node masing-masing pada hidden layer 1 dan hidden layer 2 sebanyak 5 node. Penggunaan neural network menggunakan 2 hidden layer dengan toleransi error mulai dari 0.1 sampai dengan 0.00001 memiliki tingkat keberhasilan tertinggi sampai dengan $100 \%$ untuk uang $\mathrm{Rp}$ 20.000 dan $\mathrm{Rp}$ 100.000. Apabila dilihat dari tingkat keberhasilan, pada pengujian alat memiliki tingkat keberhasilan paling rendah sebesar $93 \%$ pada mata uang Rp 50.000, dengan jumlah uang kertas yang diuji sebanyak 15 lembar.

\section{REFERENSI}

[1] detikFinance. (2010, Oktober) BI: Uang Kertas Sudah 'Ramah' untuk Tunanetra. [Online]. https://finance.detik.com/moneter/d-1460982/biuang-kertas-sudah-ramah-untuk-tunanetra

[2] TribunNews Balikpapan. (2015, Maret) Penipu Kuras Uang dari ATM Penyandang Tunanetra Ini. [Online]. https://www.tribunnews.com/regional/2015/03/10/penipu-kuras-uangdari-atm-penyandang-tunanetra-ini

[3] Rico Afrido Simanjuntak. (2018, November) Pengalaman Sedih Tunanetra, Ditipu dengan Nominal Uang Tak Sesuai. [Online]. https://nasional.sindonews.com/read/1355383/15/pengalaman-sedihtunanetra-ditipu-dengan-nominal-uang-tak-sesuai-1542381589

[4] Hanny Hikmayanti Handayani and Omar Komarudin, "Penggunaan Algoritma Backpropagation Levenberg Marquardt dan Teknik Pengolahan Citra Digital Untuk Identifikasi Nominal Uang Kertas," Jurnal Ilmiah Solusi, vol. 1, no. 2, pp. 16-33, April-Juni 2014.

[5] Dwi Aryo Porbadi, M. Rif'an, and Ponco Siwindarto, "Alat Deteksi Nominal Uang Kertas untuk Penyandang Tuna Netra," Jurnal Mahasiswa TEUB, vol. 2, no. 1, 2014.

[6] Indra Gunawan Saputra, Erwin Susanto, and Ramdhan Nugraha, "Impelemntasi Metode Jaringan Saraf Tiruan (JST) pada Alat Deteksi Nominal Uang," eProceedings of Engineering, vol. 3, no. 1, pp. 65-70, April 2016.

[7] Ridha Nur Izah, "Klasifikasi Nominal Uang Kertas Rupiah Tahun Emisi 2017 dengan Algoritma Convolutional Neural Network Menggunakan Maxnet," Jurusan Statistika, Fakultas MIPA, Universitas Islam Indonesia, Yogyakarta, Tugas Akhir Sarjana 2018.

[8] ElectronicWings. TCS3200 Colour Sensor Module. [Online]. https://www.electronicwings.com/sensors-modules/tcs3200-coloursensor-module

[9] Dyah Puspitaningrum, Pengantar Jaringan Saraf Tiruan. Yogyakarta, Indonesia: Penerbit Andi, 2006.

[10] Alan Surya, Brigita Emiliani, and Ciptadi Sutiknyo, "Music Player dengan Menggunakan Sparkfun WTV020SD," Institut Sains Terapan dan Teknologi, Surabaya, Proyek Mikroprosessor II 2016. 